\title{
Movimentos surdos e os fundamentos e metas da escola bilíngue de surdos: contribuições ao debate institucional
}

\section{Deaf movements and the bases and goals of bilingual schools for the deaf: contributions to the institutional debate}

\author{
Sandra Patrícia de Faria do Nascimento ${ }^{1}$ \\ Messias Ramos Costa ${ }^{1}$
}

\begin{abstract}
RESUMO
Nesse artigo, a trajetória percorrida pela comunidade surda de Brasília para a implantação da Primeira Escola Pública Integral Bilíngue Libras e Português-Escrito do Distrito Federal agrega-se à apresentação de uma abordagem geral e histórica do conceito buscado pelo Movimento Nacional em favor da Cultura e Educação de Surdos para as Escolas Bilíngues. Esse artigo apresenta também metas, princípios e diretrizes dessas Escolas Bilíngues, fundamentados nos estudos acadêmicos em crescente expansão nos programas de pós-graduação das universidades brasileiras, nas experiências dos alunos surdos matriculados em um sistema educacional fadado ao fracasso escolar, nas experiências dos profissionais da educação envolvidos em pesquisas que levam à melhoria da qualidade do ensino oferecido e na legislação que, timidamente, começa a absorver o paradigma educacional eleito pela comunidade surda para a construção das Escolas Bilíngues de Surdos em todo o território nacional. A partir das perspectivas lançadas nesse contexto, as primeiras instituições criadas como Escolas Bilíngues de Surdos podem ser modelos para a criação, melhoria e ampliação de Escolas Bilíngues de Surdos, das já existentes e das iminentes nos diferentes estados brasileiros.

Palavras-chave: Escola Bilíngue de Surdos; política linguística; Língua de Sinais Brasileira - Libras; Português-Escrito.
\end{abstract}

DOI: $10.1590 / 0104-4060.37021$

1 Universidade de Brasília. Brasília, Distrito Federal, Brasil ICC Sul - B1 72, mezanino, Campus Darcy Ribeiro - Asa Norte. CEP: 70.910-900. 


\begin{abstract}
In this article, the trajectory followed by the deaf community of Brasília for the deployment of the first public full time bilingual school - Libras (Brazilian Sign Language) and Written-Portuguese - adds up to the presentation of a general and historical approach of the concept pursued by the National Movement, in favor of Culture and Deaf Education for Bilingual Schools. This article also presents goals, principles and guidelines of Bilingual Schools, based on academic studies in growing expansion in graduation programs in Brazilian universities, on experiences of deaf students enrolled in an educational system doomed to failure and on experiences of pedagogues' research engaged in leading to improve the quality of the education offered and on legislation that, maidenly, begins to absorb the educational paradigm elected by the deaf community for the construction of Deaf Bilingual schools across the country. From the perspectives released in this context the first institutions established as Bilingual Schools for Deaf People can be models for the creation, improvement and expansion of Bilingual Schools for the Deaf concerning the existing ones and other such imminent in different Brazilian states.
\end{abstract}

Keywords: Bilingual School for the Deaf; language policy; Brazilian Sign Language; Written Portuguese.

Sonhei que nuvens carregadas derramavam suas águas sobre sementinhas do cerrado brasileiro. Dessas sementes surgia a Escola Bilíngue, onde só se viam mãos falando por todos os lados. Esse é um grande desafio de valorização... rega-se o terreno de onde brota a comunidade surda; rega-se o terreno de onde brota a identidade surda; rega-se o terreno de onde brota a cultura da terra. É o nascer de um novo modelo de escola bilíngue; um modelo que dá oportunidade a todos; um modelo que leva à verdadeira inclusão social dos surdos.

(Messias Ramos Costa)

\title{
Introdução
}

A trajetória percorrida pela comunidade surda de Brasília para a implantação da Primeira Escola Pública Integral Bilíngue Libras e Português-Escrito do Distrito Federal, ao lado da trajetória geral e histórica dos princípios e diretrizes que sustentam essa escola, desvela-se nesse artigo e pode ser estendida a outras Escolas Bilíngues de surdos já existentes e às iminentes nos diferentes estados brasileiros. 
Cada indivíduo deve ter garantido o seu direito inalienável à educação, sendo respeitadas suas especificidades e necessidades, seu direito de ir, vir, estar e expressar-se onde se sente melhor. Assim, diante do universo diverso no qual encontram-se as mais diferentes pessoas, oferecer educação de qualidade a todos não pode significar oferecer a mesma educação para todos.

Os próprios surdos são os atores das manifestações que clamam por uma educação bilíngue preparada para eles. Lideram o movimento aqueles que conseguiram alçar voos, mesmo após vivenciarem um sistema educacional deficiente, quando vítimas dele nos bancos escolares. Nenhum outro ator desse contexto sabe dizer melhor como devem aprender os surdos do que aqueles que têm a Libras como primeira língua. Por isso, a proposta de uma educação bilíngue, que institucionaliza a Libras como primeira língua de instrução direta, sem mediação, e a Língua Portuguesa escrita como segunda língua, significa muito mais que um simples deslocamento de espaço físico e está longe de ser uma ação segregadora, como alguns insistem em afirmar. Todo educador, todo político, todo ser ético deve nutrir um sentimento de empatia pelo outro; não se deve avaliar o outro pela sua ótica senão pela ótica do outro.

Os espaços educacionais específicos para o ensino, conforme proposto pela comunidade surda brasileira, exigem uma mudança abrupta de paradigma; muda-se o foco educacional da audição ausente na orelha do surdo para a competência linguística e para o potencial cognitivo que o surdo tem; o que significa oferecer a oportunidade de acesso real e concreto a todo tipo de conhecimento construído e alcançado pelo ser humano. Em síntese, uma escola bilíngue erguida sobre os princípios norteadores na proposta que ora se apresenta tem como consequência a verdadeira inclusão dos surdos na sociedade.

As especificidades dos surdos precisam ser respeitadas e, portanto, é preciso também que a sociedade aceite participar desses espaços onde essa diversidade existe e convive harmoniosamente com regras que podem ser adotadas para todos, surdos e ouvintes, mas a partir de outro paradigma. Para entender-se como esse paradigma precisa ser edificado é preciso compreender, antes, o que vem a ser uma Escola Bilíngue de Surdos.

\section{O que é uma Escola Bilíngue de Surdos?}

De uma maneira geral, quando se fala em Escola Bilíngue e educação bilíngue, percebe-se que não há uma clareza do seu significado. É comum as pessoas confundirem Escola Bilíngue com uma escola de inglês ou uma escola 
em que se ensina outra língua estrangeira. E nesse contexto, ambíguo e confuso, encontra-se também o Capítulo VI do Artigo 22 do Decreto $n^{\circ} 5.626$ (BRASIL, 2005), ao mencionar a organização de "escolas e classes de educação bilíngue, abertas a alunos surdos e ouvintes, com professores bilíngues [...]".

Esse inciso traz uma ambiguidade geradora de uma confusão conceitual na percepção do que vem a ser uma Escola Bilíngue e uma sala de aula bilíngue. $\mathrm{O}$ fato de se ter uma escola aberta a surdos e ouvintes não implica oferecer uma educação bilíngue. Há uma confusão generalizada a esse respeito. Virou senso comum afirmar que uma sala bilíngue é aquela em que há matriculados estudantes surdos e ouvintes; surdos que falam libras e ouvintes que falam a língua portuguesa. Educação bilíngue, entretanto, é aquela que oferece instrução em duas línguas.

Na proposta da Escola Bilíngue, essa garantia precisa estender-se para toda a educação básica e incluir a educação bilíngue precoce, a fim de garantir o acesso linguístico de toda criança surda ou deficiente auditiva, implantada ou não, às duas línguas a que têm acesso, na modalidade em que têm acesso.

Há dois tipos básicos de escolas bilíngues que oferecem a Libras e a Língua Portuguesa Escrita como línguas de instrução. Um tipo de escola bilíngue é a ESCOLA BILÍNGUE DE SURDOS, onde apenas os estudantes surdos têm acesso à matrícula, como é o caso do INES. Outro tipo de escola bilíngue é a ESCOLA BILÍNGUE LIBRAS E PORTUGUÊS-ESCRITO, onde estudantes surdos e ouvintes podem ser matriculados, como é o caso da Primeira Escola Bilíngue Libras e Português-Escrito de Taguatinga. O que há de comum entre as duas é o fato de que, em ambas, a Libras e o português-escrito são as línguas de instrução e ensino; o que difere uma da outra é o estudante. Nos dois tipos de instituição, o professor deve ser bilíngue. A contratação ou o preenchimento de carências de profissionais ouvintes não bilíngues, que tiverem de atuar com a presença de um intérprete em sala de aula, é provisória, pois ocorre apenas enquanto o professor regente se forma bilíngue ou enquanto se encontra um profissional bilíngue para a área de conhecimento em questão.

$\mathrm{Na}$ Escola Bilíngue que aceita matrícula de estudantes ouvintes, esses estudantes deverão ser bilíngues, ou deverão tornar-se bilíngues. Por isso, é aconselhável que pais interessados em matricular seus filhos ouvintes ainda não bilíngues, numa escola bilíngue, efetivem a matrícula o mais precocemente possível para não atrasar o período de aquisição linguística da Libras e adaptação do estudante ouvinte à metodologia da instituição. Isso ocorre porque os estudantes ouvintes não terão tradutores-intérpretes para verter as aulas ministradas em Libras para a Língua Portuguesa, uma vez que todo o ensino e toda a comunicação da instituição é realizada preponderantemente em Libras. 
A Escola Bilíngue é uma síntese do que há muitos anos tem-se priorizado como demanda da comunidade surda brasileira; é a representação do que nas duas últimas décadas vem sendo descrito, relatado e analisado nos trabalhos acadêmicos, cada dia mais expressivos em quantidade e qualidade; e, por fim, é uma instituição que passa a fazer parte da sociedade brasileira, com a histórica e expressiva conquista do Movimento Nacional em Favor da Educação e da Cultura Surda, liderado pela Federação Nacional de Educação e Integração dos Surdos - FENEIS: a garantia de uma Política de Educação de Surdos ampla e diversificada, que oficializa e legaliza as escolas bilíngues por meio da sanção, pela Presidenta Dilma, em 25 de junho de 2014, da Lei Federal no 13.005, que regulamenta o Plano Nacional de Educação, em vigor de 2014 a 2024.

\section{Os fundamentos da educação bilíngue oferecida nas Escolas Bilíngues}

Conhecer os fundamentos da educação bilíngue a ser oferecida nas Escolas Bilíngues é fundamental para se entender melhor ainda o que são as Escolas Bilíngues de Surdos. Diferentemente do que ocorria no início desse milênio, já não são mais recentes nem também são poucas as pesquisas e os documentos que nos levam a entender e a reconhecer a Escola Bilíngue como um espaço adequado ao aprendizado eficiente e eficaz das crianças surdas.

A questão linguística é o principal diferencial de toda proposta de educação a ser ofertada para os surdos, e a oferta de educação bilíngue em Escolas Bilíngues é consequência desse diferencial, recomendado a partir do que tem sido coletado, analisado e fundamentado nas pesquisas que surgiram com a visibilidade dada às línguas de sinais e aos estudos surdos após as pesquisas de Stokoe (1960).

A educação bilíngue não pode ocorrer de qualquer forma e a qualquer custo, pois não se reduz a qualquer espaço educacional onde se agrupam surdos e ouvintes; não se reduz a qualquer ambiente onde esteja presente um profissional que fez algum curso de Libras e que "tem ou não" fluência em Libras, ou que "tem ou não" domínio do conteúdo a ser traduzido. O simples agrupamento de pessoas diferentes, com características diferentes e com necessidades diferentes não acarreta a inclusão.

Assumir uma postura restritiva fere os princípios que fundamentam as escolas bilíngues, bem como o justo conceito de equidade. É preciso incluir com equidade, que significa incluir com "disposição para reconhecer imparcialmente o direito de cada um [...] com senso de justiça, imparcialidade, isenção, 
neutralidade etc. ${ }^{2}$. A figura dos garotos assistindo a um jogo de futebol sobre caixotes atrás de um cercado de madeira (víde figura 1) é bastante elucidativa desse conceito. A oferta de um mesmo ensino a todos não garante acesso, nem qualidade.

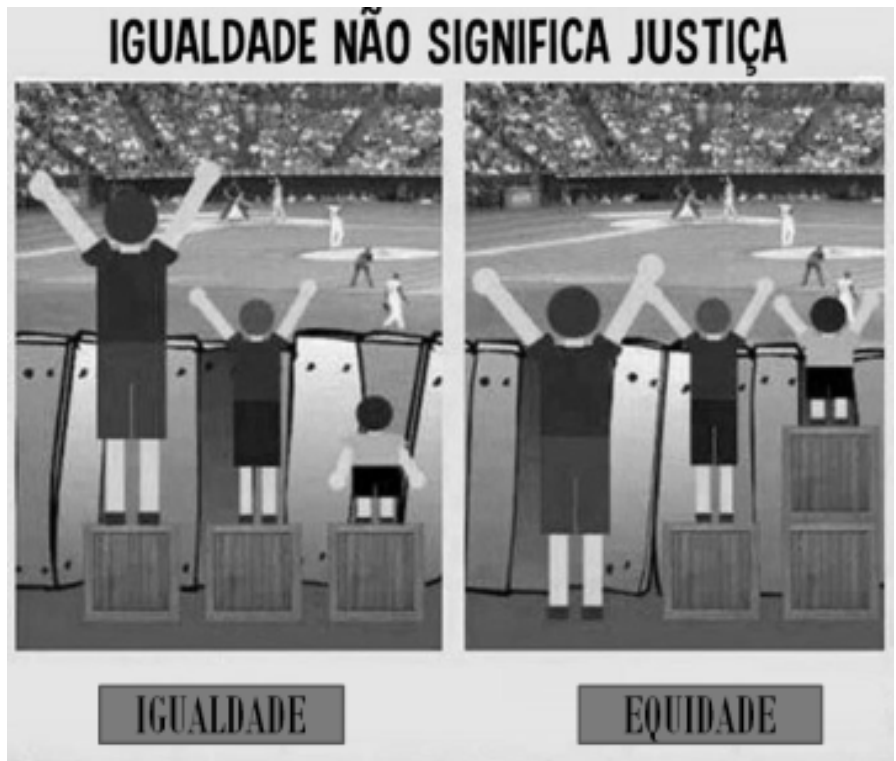

FIGURA 1 - EQUIDADE

FONTE: Adaptada de <http://missrobarts.weebly.com/uploads/1/7/ 1/7/17177220/8628972_orig. jpg>. Acesso em: 18/04/2014.

A esse respeito, Sá (2011, p. 17) faz a voz de uma enorme quantidade de surdos e pesquisadores brasileiros ao defender que "a escola é um direito de todos, mas não a mesma escola, não a mesma proposta, pois a mesma escola não atende às necessidades e especificidades de todos".

Se os indivíduos são diferentes, um único modelo educacional não pode funcionar para todos, sob a alegação de que se está ofertando uma educação inclusiva. Ser inclusivo não significa oferecer o mesmo ensino a todos ou misturar todos os estudantes numa mesma sala de aula. Ser inclusivo implica "promover o bem de todos, sem preconceitos de origem, raça, sexo, cor, idade e quaisquer outras formas de discriminação", como defende o artigo 205 da Constituição Federal (BRASIL, 1988).

2 Fonte: $<$ http://www.dicio.com.br/equidade/>. 
Se a visão é o principal canal de comunicação e o mais natural de um indivíduo, por que não aproveitar-se desse canal para oferecer um ensino de qualidade? Essa constatação leva a uma óbvia proposição que não tem sido tratada como óbvia: a educação oferecida para pessoas visuais deve contemplar um currículo visual, uma pedagogia visual, uma metodologia visual e, nesse contexto, a avaliação também precisa ser visual. Se a Libras e o Português-Escrito propiciam "visualidade" ao ensino, são essas as formas de instrução mais acessíveis dentro das escolas onde estudam surdos brasileiros e, portanto, é nesse viés que o ensino deve ser programado para as Escolas Bilíngues.

Sendo essa visualidade acessível a surdos e ouvintes, escolas bilíngues podem, ainda, ser organizadas como espaços inclusivos para a oferta de uma educação visual para surdos e ouvintes, desde que o princípio da isonomia aos surdos, e das formas de apresentação das línguas, não viole o princípio da visualidade educacional, princípio esse que precisa ser garantido e preservado dentro de todas as Escolas Bilíngues de Surdos.

A convicção que tínhamos e a comprovação científica que se tem hoje, de que a oferta de uma educação visual nas escolas bilíngues resulta no êxito educacional dos estudantes, não é fruto da mera opinião de um grupo, nem de uma visão "paternalista", protetora de indivíduos supostamente acomodados em busca de uma zona de conforto longe de escolas onde são assediados pela imposição de práticas orais da língua portuguesa. Muito pelo contrário, os estudantes surdos têm sede de conhecimento e querem o direito de acesso a todo conhecimento que os estudantes ouvintes têm.

O paradigma que ora é defendido para a educação bilíngue oferecida nas Escolas Bilíngues não é novo haja vista os estudos de Ferreira-Brito (1995), Quadros (1997), Fernandes (1998; 2006), Lacerda (1998), Skliar (1997), Sá (2011), entre outros. Vinte anos se passaram para que falar em Escola Bilíngue pudesse vir a ser realidade. Um período bastante longo para um tempo em que a tecnologia está ao alcance de todos e acelera o acesso a todo tipo de informação e pesquisa. Contudo, se tiver sido o período necessário para que as pesquisas acadêmicas tomassem corpo e força para intervir nas ações políticas e educacionais de nosso país e a voz da comunidade surda pudesse ecoar com força e respeito, vamos considerar esse momento como uma conquista.

As pesquisas que emergem desse cenário trazem elementos que fundamentam as Escolas Bilíngues com a natureza da que emergiu no Distrito Federal. Moura (2011, p. 161) reforça a necessidade de acesso linguístico pleno quando destaca que "o indivíduo Surdo, como qualquer outro indivíduo, precisa de uma comunicação completa, precisa de uma língua que lhe permita navegar pelo conhecimento de forma completa. Não há outra forma de aprender, não há outra forma de se poder obter conhecimento". 
O direito linguístico dos surdos de adquirirem uma língua de sinais se justifica cientificamente nos estudos de Quadros em que ela explica a importância de se mudar as formas de se tratar a educação dos surdos, esclarecendo que:

A diferença na modalidade da língua e do acesso a ela implica diferença na forma de aquisição dessa língua. Os surdos privilegiam o visual-espacial e a língua de sinais é visual-espacial. Vários estudos (Meier, 1980; Loew, 1984; Lillo-Martin, 1986; Petitto, 1987; Karnopp, 1994; Quadros, 1995) evidenciam que o processo das crianças surdas adquirindo língua de sinais ocorre em período análogo à aquisição da linguagem em crianças adquirindo uma língua oral-auditiva. (QUADROS, 2005).

Seguem esse mesmo escopo as palavras de Skliar (1997/2004): “crianças surdas devem crescer bilíngues, tendo a língua de sinais como sua primeira língua e a língua majoritária, na modalidade escrita, como segunda língua e terem a oportunidade de acesso a uma educação bilíngue e bicultural". E Sanchez explica como esse processo bilíngue deve ocorrer para as pessoas surdas:

[...] o bilinguismo, no caso dos surdos, pressupõe o acesso pleno à língua de sinais como primeira língua, representando o elemento fundador de sua subjetividade na constituição de sentidos sobre o mundo e acesso ao conhecimento. Isto assegurado, o aprendizado das línguas que a sucederão serão decorrentes da necessidade interativa significativa com o meio social em que se inserem e, certamente, a aprendizagem significativa será dependente, em maior grau, da função social atribuída a essa segunda língua nas relações cotidianas do aprendiz, do que pela imposição de uma proposta escolar planificada (SÁNCHEZ, 2002).

Fernandes (2008, p. 1 e 4 respectivamente) resgata o período de instalação desse novo paradigma no Brasil, ao lembrar que "a década de 1990 representa um marco transformador em relação aos paradigmas até então vigentes na educação de surdos", ao mesmo tempo em que prevê que "o reconhecimento dos surdos como grupo linguístico minoritário" considera "a necessidade de políticas públicas que viabilizem o aprendizado da língua brasileira de sinais Libras como sua língua materna e assegurem a língua portuguesa como segunda língua no currículo escolar". 
Foi no sentido de garantir o respeito às suas potencialidades e aspirações que os surdos foram às ruas de todo o país para pedir a manutenção de instituições de surdos existentes e a criação de Escolas Bilíngues de Surdos. E a necessidade de políticas públicas que atendam à necessidade educacional dos surdos é urgente, uma vez que nas escolas até hoje instituídas o fracasso educacional dos surdos não se encontra "banido". Muito foi melhorado, mas muito ainda falta. Em 1998, Souza denunciava que:

[...] o bilinguismo dos surdos praticado no Brasil é incipiente por inúmeras razões: a ausência de uma política linguística oficial de difusão e preservação da Libras, que contribua para a consolidação de seu status linguístico e valorização nacional; a falta de uma política linguística escolar que atribua à Libras a qualidade de língua principal para o ensino - o que requereria, além dos professores não-surdos fluentes em Libras, educadores surdos que contribuiriam culturalmente no planejamento e na execução das políticas e práticas educacionais; as fortes pressões exercidas sobre os surdos para o domínio do português, o que acaba conduzindo ao monolinguismo (cf. SOUZA, 1998).

A tarefa não é fácil. Quadros esclarece que a ausência de uma política linguística adequada acarretou resistência por parte de muitos surdos:

Diante de uma política de subtração linguística aplicada aos surdos em que o português deveria ser a única língua a ser adquirida, os surdos negam esta língua por ter representado por muitos anos uma ameaça ao uso da língua de sinais. Essa realidade implica processos de delimitação de fronteiras e de poderes. [...] Nas tessituras das propostas atuais de educação de surdos, encontramos muitos indícios desta postura: a língua de sinais é vista como secundária. Os surdos politizados já não aceitam mais isso [...] Assim, a educação de surdos na perspectiva bilíngue toma uma forma que transcende as questões puramente linguísticas. Para além da língua de sinais e do português, esta educação situa-se dentro do contexto de garantia de acesso e permanência na escola. Essa escola está sendo definida pelos próprios movimentos surdos: marca fundamental da consolidação de uma educação de surdos em um país que se entende equivocadamente monolíngue (QUADROS, 2005). 
E Fernandes (1998) acrescenta que as mudanças necessárias a esse paradigma de educação de surdos não podem limitar-se à pura aceitação da entrada da língua de sinais dentro da escola; vai muito além dessa questão. Ela explica que:

Há inúmeras ações a serem praticadas que envolvem um projeto de educação, que considere em sua proposta curricular o legado histórico e cultural das comunidades surdas, novas tecnologias educacionais pautadas essencialmente em recursos visuais, formação de professores edificadas em concepções socioantropológicas, maior participação da comunidade surda na gestão dessa educação, entre outros aspectos (FERNANDES, 1998, p. 183).

A lentidão da incorporação de novas perspectivas nas políticas públicas educacionais parece estar relacionada ao fato de não ter havido um "casamento" anterior entre o conhecimento acadêmico construído com a atualização da legislação e a ação mobilizadora do movimento social surdo. Com a proximidade das discussões presentes nos contextos citados, a Escola Bilíngue deixa de ser um desiderato e passa a ser uma demanda com emergência de concretização. Os fundamentos para essa busca são mais claros; mais pesquisadores vão a campo e, além de constatarem a realidade, comprovam os resultados positivos de uma prática mais próxima à da educação bilíngue ideal. Esses avanços levam a uma maturidade acadêmica visivelmente refletida na proposição de Sá a respeito da Escola Bilíngue. Segundo ela:

[...] a escola bilíngue específica para surdos tem seu valor ampliado pelo fato de que é o único tipo de escola que mais adequadamente pode configurar-se como um ambiente linguístico natural favorável à aquisição da língua de sinais em idade precoce [...] os surdos, bem como os estudiosos que defendem a escola específica para surdos, não querem a criação de guetos; querem a criação de espaços garantidos para que o surdo se torne mais rapidamente uma pessoa "bilíngue", e, para tanto, precisa de um ambiente linguístico natural para a aquisição de sua primeira língua, a partir do qual terá condições de desenvolver sua consciência metalinguística, ampliando as possibilidades de aprendizagem da segunda língua (SÁ, 2011, p.17-19 e 22). 
Todas essas reflexões reforçam que criar Escolas Bilíngues não basta; é preciso garantir que a educação nelas oferecida seja bilíngue, de fato. Por isso o alerta de Sá: uma

[...] escola/classe específica não garantirá o êxito pleno apenas pelo fato de nela se colocar estudantes surdos, professores surdos e ter a língua de sinais como língua de instrução - visto que não é a proposta que garante a qualidade [...]. A "melhor" escola para os surdos é a escola que lhes dá acesso, permanência e sucesso educacional; é aquela na qual eles podem reconstruir seu próprio processo educacional; é aquela que possibilita trocas culturais e o fortalecimento do discurso dos surdos; é aquela na qual as comunidades surdas manifestam sua própria produção cultural e suas próprias formas de ver o mundo. Minha defesa pela escola/classe específica para surdos é o entendimento de que estes itens não poderão acontecer com naturalidade numa escola onde os surdos são minoria, onde a definição da surdez se dá a partir do déficit auditivo e onde sua língua e cultura não são priorizadas (SÁ, 2011, p. 55).

Fernandes reforça esse alerta, ao explicar que:

a educação bilíngue certamente não se concretizará na escola comum que aí está e, tampouco, na escola especial que aí está. Tanto uma como a outra são produtos históricos da violência simbólica e cultural que narrou os surdos como seres menos dotados, ignorando-lhes as diferenças ou promovendo a assimilação da cultura e línguas majoritárias, em detrimento de suas idiossincrasias. (FERNANDES 2006, p. 122-123).

As Escolas Bilíngues brasileiras precisam ser erguidas sobre o paradigma da diferença. É preciso destituir o paradigma da deficiência sobre o qual foi edificada toda a educação especial na qual as pessoas surdas foram agrupadas e submetidas. Por isso também não basta dizer que as tradicionais escolas (especiais) de surdos passaram a ser chamadas de escolas bilíngues. Elas são escolas especiais que podem ser transformadas em escolas bilíngues. Algumas já têm passado por esse processo, mas precisam estar atentas, a fim de que não sofram apenas mudanças superficiais sob a manutenção de uma filosofia embrenhada de métodos de ensino repetidores das mesmas limitações existentes no sistema 
anterior. Nesse sentido, as escolas de surdos precisam autoavaliar-se, e as políticas públicas voltadas ao eixo educacional precisam ser revistas.

É imprescindível desvincular dos surdos o olhar sobre seus ouvidos; olhar esse que remete a uma visão patológica implicada numa intervenção medicalizante, como tentativa de aproximar o surdo de uma pessoa não surda, por meio da recuperação dos resíduos de sua audição, com o apoio interventivo da tecnologia disponível. Paralelamente, é imprescindível vincular ao surdo o olhar sobre suas mãos; olhar que remete a uma visão socioantropológica e multicultural da pessoa surda; um olhar que identifica os surdos como membros de uma comunidade linguística minoritária, com uma língua absolutamente plena, e características essencialmente visuais que acarretam a assimilação do mundo e do conhecimento visualmente.

Os argumentos em favor das Escolas Bilíngues são legitimados pelos próprios surdos. Perlin e Miranda (2011) iniciam sua defesa explicando que:

O surdo, em primeiro lugar, tem de saber sua língua, sua cultura, e também aprender o mesmo que o ouvinte aprende, para poder interagir com ele. Digamos que o surdo nunca vai viver num gueto, como preconizam, mas que vai interagir continuamente no campo ouvinte (PERLIN; MIRANDA, 2011, p. 109).

As Escolas Bilíngues de Surdos são uma resposta ao desejo de propiciar o desenvolvimento autônomo e proativo dos estudantes surdos. São um desejo latente na literatura produzida por todos os pesquisadores mencionados nessa seção. Como diz Moura (2011, p. 166), "se desejamos uma educação real para o surdo, em que ele seja colocado no lugar de capaz de se gerir e de aprender, apreendendo o mundo e tudo que lhe cerca, temos que sair desse modelo já consagrado, seja da educação especial, seja da inclusão e partir para um modelo de escola bilíngue".

Fernandes destaca que:

[...] em projetos bilíngues é pressuposto que o processo de ensino e de aprendizagem está fundado em operações linguísticas e metalinguísticas em que a primeira língua mobilize os sentidos e as estratégias de aproximação com a segunda língua em questão, ou seja, o aprendizado do sujeito será mediado pelas experiências que desenvolveu em sua língua materna, de referência. $(2008$, p. 6). 
E antes disso, em 2006, Fernandes já tinha a clareza de que:

a escola representa para o aluno surdo o lugar privilegiado para a aquisição da língua de sinais, oportunizada pela interação com seus pares surdos e professoras bilíngues, além de ser o espaço exclusivo para a aprendizagem acadêmica e acesso ao conhecimento formal (FERNANDES, 2006, p.78).

A pesquisa de Capovilla, amplamente citada nos documentos da FENEIS, traz dados quantitativos que tornam irrefutável a necessidade da criação de Escolas Bilíngues de Surdos e a expansão das Escolas Bilíngues existentes:

Ao longo de uma década, o Pandesb examinou 9.200 estudantes surdos brasileiros do $1 .^{\circ}$ ano do ensino fundamental até o ensino superior de 15 estados brasileiros representando todas as regiões geográficas do Brasil. [...] Os resultados mostram que os estudantes surdos aprendem mais e melhor em escolas bilíngues (CAPOVILLA apud SÁ, 2011, p. 86-87).

Foram essas pesquisas acadêmicas citadas, além de outras, respaldadas pela comunidade surda brasileira, a qual se mobilizou em defesa de seu reconhecimento, que levaram à sanção da Lei n ${ }^{\circ}$ 10.436, em 24 de abril de 2002, que reconhece a língua de sinais brasileira como meio legal de comunicação e expressão e como sistema linguístico de natureza visual-motora, com estrutura gramatical própria para transmissão de ideias e fatos oriundos de comunidades de pessoas surdas do Brasil (BRASIL, 2002), entre outras que fundamentam as Escolas Bilíngues.

A visibilidade do Movimento Surdo em defesa das Escolas Bilíngues alcançou vários segmentos da sociedade, que tem estado mais aberta às especificidades da educação de surdos. Pesquisadores não diretamente ligados a pesquisas na área da surdez já estão sensibilizados com a questão da educação dos surdos e o direito que eles têm de optar pela educação que querem. Esse é o caso de Carvalho, que durante a Conferência Nacional dos direitos da Pessoa com deficiência, ocorrida em Brasília em 2001, apelou aos presentes:

Se o lema da Convenção é Nada sobre Nós sem Nós, porque não reconhecer as reivindicações dos surdos e transformar o pronome pessoal 
/nós/ em seu homônimo/ nós/, isto é, num laço muito apertado e difícil de desatar? (CARVALHO, 2012).

A Escola Bilíngue de Surdos ergue-se fundamentada primeiramente nos direitos alienáveis do ser humano. No direito humano de ser, de pertencer a um grupo e por ele ser respeitado; no direito linguístico de possuir uma língua com a qual seja possível interagir com a sociedade e ter acesso pleno à informação e ao conhecimento; no direito de receber uma educação transformadora, que torne sua vida melhor; no direito de exercer sua cidadania com autonomia, liberdade de expressão e protagonismo, associado aos deveres que essa condição lhe exige.

Todos esses direitos, respaldados em pesquisas etnográficas, de campo, entre outras das mais distintas naturezas, ampliam o leque de oportunidades e de possibilidades das pessoas surdas e apontam caminhos para ações necessárias à implantação e implementação da educação bilíngue em Escolas Bilíngues nos eixos políticos, sociais e educacionais.

\section{Uma retrospectiva da histórica luta pela Escola Bilíngue no Distrito Federal}

Se a luta é por uma Escola Bilíngue onde seja oferecida uma educação bilíngue, o principal diferencial da instituição está nas duas línguas a partir das quais todo o ensino é oferecido aos estudantes.

No Distrito Federal - DF, a luta pela Escola Bilíngue durou mais de doze anos. Durante esse período, dois argumentos dos gestores da Secretaria de Educação do Distrito Federal - SEDF lideraram a lista de empecilhos para a criação da Escola Bilíngue. O primeiro deles esteve constantemente associado ao fato de o Distrito Federal já possuir uma instituição de surdos, o Centro Educacional de Audição e Linguagem Ludovico Pavoni - CEAL, que nunca omitiu o fato de que a instituição defende e aplica uma abordagem educacional oralista. Os gestores argumentavam que não havia justificativa para a criação de outra instituição de surdos no DF, mesmo sob o argumento de que a abordagem educacional para a outra instituição pleiteada era de uma educação bilíngue, totalmente diferenciada da proposta da instituição existente.

Outro empecilho para a criação de uma Escola Bilíngue no DF vinha sendo o equivocado julgamento de gestores e técnicos organizadores da política educacional local a respeito de quem é o sujeito surdo, seus limites e potencialidades. 
Em sua grande maioria, os gestores desconhecem a natureza dos surdos sob o prisma da diferença e, portanto, enquadram-nos no paradigma da deficiência, sobre o qual foi erigida, por anos, a política educacional dos surdos defendida nos documentos oficiais, não somente no $\mathrm{DF}$, mas em todo o país.

Essa política ignora os apelos dos surdos por uma participação efetiva na definição do modelo educacional que lhes traga o efetivo aprendizado. Essa mudança de paradigma implica romper a perspectiva educacional patológica para erigir a perspectiva educacional socioantropológica, imbuída de concepções linguísticas, posto esse ser o foco principal do novo paradigma, que rompe a política opressiva de imposição de uma educação medicalizadora, que insiste em patologizar os métodos educacionais.

Muitos surdos, conscientes dessa realidade, conseguiram fugir do assujeitamento intelectual a que foram submetidos; entenderam-se vítimas de uma "sabotagem educacional" e conquistam, quase que forçadamente, o direito de escolher o formato da educação bilíngue que desejariam ter tido e que desejam para os surdos das novas gerações, a fim de reverter o contexto opressivo instaurado.

Persiste o consenso infundado de que os surdos precisam incluir-se com os não surdos para evitar a segregação. Esse argumento é frágil; ignora a condição linguística dos surdos, que precisa ser foco principal dessa questão. Antes, os surdos devem estar incluídos com seus pares falantes nativos da Língua de Sinais, de forma a se garantir tanto a aquisição da Língua de Sinais no período mais propício e da forma mais natural possível, quanto o acesso a todo o conhecimento por meio da Libras e de uma metodologia visual que alicerce e subsidie a Educação Bilíngue a lhes ser oferecida.

A FENEIS-DF, apoiada por seus líderes surdos, alguns dos quais ex-estudantes da SEDF, participou da luta pela criação da Escola Bilíngue no DF, desde 1998, quando esses mesmos líderes, à época estudantes, participaram de um Programa de Formação de Professores Surdos, denominado "Programa Surdo Educador", iniciado no DF, em 1995, e interrompido em dezembro de 2004, quando a SEDF deixou de oferecer o curso de Magistério a nível médio, à ocasião conhecido como segundo grau profissionalizante.

Como desdobramento do Movimento Nacional, a FENEIS-DF buscou o apoio de professores da SEDF, que atuam diretamente na educação de surdos há mais de 10 anos e que entendem a importância de a educação tomar um rumo que leve ao aprendizado efetivo dos estudantes surdos. A partir dessa parceria, a busca pela criação da Escola Bilíngue na capital do país ecoou nos corredores da Câmara Legislativa do Distrito Federal e nas plenárias da mesma Casa, marcada por manifestações dos surdos brasilienses, iniciadas com a visita da FENEIS-DF a parlamentares distritais, o que resultou numa maior proximidade entre o Movimento e os Poderes Legislativo e Executivo locais. 
Nessa liderança, a FENEIS-DF elaborou e divulgou um Projeto, posteriormente endossado pela FENEIS Nacional, sobre o qual foi elaborado um Projeto de Lei, aprovado por unanimidade na Câmara Legislativa do Distrito Federal, que resultou na Lei $\mathrm{n}^{\circ}$ 5.016, publicada em 15 de janeiro de 2013, após sanção do então governador em exercício. Essa conquista acarretou a transformação da Escola Classe 21 de Taguatinga em Escola Bilíngue Libras e Português-Escrito de Taguatinga e os desdobramentos subsequentes a essa transformação, incluindo a elaboração do Projeto Político-Pedagógico da Instituição por uma Comissão Instituída pela SEDF para auxiliar e acompanhar a implantação e implementação da instituição no DF.

Esse Movimento defende uma escola PÚBLICA, porque os governos federal, estadual, municipal e distrital são responsáveis por oferecer o ensino gratuito aos estudantes, indiscriminadamente; INTEGRAL, porque é preciso oferecer aos estudantes uma formação em tempo integral, posto o fato de a sociedade não estar apta a prepará-los para a vida fora da escola. A sociedade não está pronta para acolher os estudantes em todas as esferas, sem formação específica; a acessibilidade na sua plenitude é ainda utópica. Além disso, a formação dos estudantes não pode restringir-se à formação acadêmica, conteudista, propedêutica. É preciso oferecer uma formação integral, que possa permitir ao estudante o seu desenvolvimento global, físico e mental ao lado da sua inclusão no mundo tecnológico e digital em que vivemos. Defende-se, especialmente, uma escola BILÍNGUE, porque, para a instrução específica dos estudantes surdos, a escola precisa estar apta a oferecer, em sua integralidade, duas línguas (Libras e Português-Escrito), embora como disciplina também possam ser oferecidas aulas de inglês-escrito, espanhol-escrito, além de outras línguas de sinais como a Língua Americana de Sinais - ASL, a Língua Francesa de Sinais - LSF, entre outras.

A Escola Bilíngue também é REGULAR, porque contempla o currículo de base nacional; é ESPECIALIZADA, porque o profissional que nela atua precisa de um conhecimento especializado na área, precisa ser fluente em Libras, precisa conhecer e estar disposto a trabalhar com a metodologia proposta e necessária ao desenvolvimento de um Plano didático-pedagógico diário adequado aos estudantes surdos, fator fundamental para atender a essa proposta institucional; ESPECIALIZADA, ainda, porque o currículo é adequado e suplementado com Disciplinas não incluídas no currículo regular convencional. A fim de tornar o currículo mais próximo do estudante, as Disciplinas de Libras são introduzidas em todas as etapas de ensino e substitui-se a Disciplina de Língua Portuguesa como primeira língua pela mesma Disciplina como segunda língua, considerando-se as especificidades identitárias e multiculturais, imprescindíveis à educação que envolve estudantes surdos. É nesse sentido que a Literatura 
Surda e a Literatura Visual também precisam ser contempladas nas Escolas Bilíngues ao lado da Literatura Universal. Por fim, a Escola Bilíngue é também ESPECÍFICA, porque o estudante que nela estuda opta por essa modalidade de ensino, seja ele surdo ou ouvinte.

Nesse sentido, a Escola Pública Integral Bilíngue Libras e Português-Escrito é uma escola aberta à matrícula de estudantes surdos que têm a Libras como primeira língua e de estudantes ouvintes que nela percebem a possibilidade de tirar proveito de uma educação que tenha a língua de sinais e a língua portuguesa escrita como línguas de comunicação, instrução e ensino.

A Libras está presente na interação comunicativa no ensino dos conteúdos, no material didático e nas provas. O Português-Escrito está presente nos cartazes, nos avisos, nos murais, nos quadros, nos livros, na internet e nos demais instrumentos impressos empregados na escola. Como meio de interação, o Português-Escrito está presente nos chats, emails, nos fóruns de estudos, nas discussões via web, torpedos, whats app etc.

Essa escola contempla a realidade dos estudantes a quem se destina, com uma efetiva proposta inclusiva, pois ergue-se sobre os princípios da inclusão social e humana, necessários ao desenvolvimento global do indivíduo, em prol da formação no indivíduo de um verdadeiro sentimento de pertencimento à sociedade.

\section{Considerações finais}

Um longo percurso já foi percorrido. Entretanto, ainda falta muito a percorrer. $\mathrm{O}$ fato é que as Escolas Bilíngues, enfim, são uma realidade. Urge a reorganização das escolas de surdos para se tornarem efetivas Escolas Bilíngues e a criação de novas escolas que já nasçam alicerçadas nos novos paradigmas que devolvam aos surdos, cidadãos brasileiros, e a toda a sociedade, o direito de viver em harmonia na diversidade, o direito de aprender bem e melhor, onde se sentem bem e onde melhor atende-se às necessidades dos indivíduos.

A Escola Bilíngue, como um espaço para aquisição de uma língua visual, é muito mais que um espaço educacional inclusivo, mas um espaço educacional onde, as línguas propostas para instrução e ensino, despertam, nos indivíduos que dela tiram proveito, funções cognitivas a mais, além das promovidas em escolas monolíngues e lusófonas.

Enquanto a sociedade não compreender que a educação bilíngue amplia as perspectivas sociais, culturais e cognitivas do indivíduo, as Escolas Bilíngues 
serão vistas apenas como escolas de surdos. No dia, porém, que a sociedade estiver pronta para entender os benefícios que as Escolas Bilíngues oferecem para os surdos e para os ouvintes, a sociedade estará apta a entender o que é incluir, o que é ser verdadeiramente incluído e inclusivo.

Anima-nos o fato de que, no contexto da Escola Bilíngue de Surdos defendida pela comunidade surda brasileira, os conceitos de inclusão, equidade, igualdade, ação afirmativa, direito, dever e isonomia estão sendo redefinidos com um olhar mais humano, a cada dia mais conhecidos e praticados de forma mais justa; o que torna possível mais surdos brasileiros melhor exercerem sua cidadania de forma consciente.

\section{REFERÊNCIAS}

BRASIL. PL-08035/2010. Aprova o Plano Nacional de Educação para o decênio 20112020 e dá outras providências (em tramitação). Disponível em: $<$ http://www.camara.gov. br/proposicoesWeb/fichadetramitacao?idProposicao=490116>. Acesso em: 23/03/2014.

. Decreto n. ${ }^{\circ} 5.626$, de 22 de dezembro de 2005. Regulamenta a Lei n. ${ }^{\circ} 10.436$, de 24 de abril de 2002 que dispõe sobre a Língua Brasileira de Sinais - Libras, e o art. 18 da Lei n ${ }^{\circ}$ 10.098, de 19 de dezembro de 2000. Diário Oficial da União, Brasília, DF, 23 dez. 2005. Disponível em: <http://www.planalto.gov.br/ccivil_03/_ato2004-2006/2005/ decreto/d5626.htm>. Acesso em: 23/03/2014.

. Lei n. ${ }^{\circ}$ 10.436, de 24 de abril de 2002. Dispõe sobre a Língua Brasileira de Sinais - LIBRAS e dá outras providências. Diário Oficial da União, Brasília, DF, 25 abr. 2002. Disponível em: <http://www.jusbrasil.com.br/legislacao/99492/lei-de-libras-lei-10436-02>. Acesso em: 23/03/2014.

. Constituição da República Federativa do Brasil. Brasília: Imprensa Oficial, 1988. Disponível em: <http://www.planalto.gov.br/ccivil_03/constituicao/constitui\% C3\%A7ao.htm>. Acesso em: 23/03/2014.

CAPOVILLA, Fernando C. Sobre a falácia de tratar as crianças ouvintes como se fossem surdas, e as surdas, como se fossem ouvintes ou deficientes auditivas: pelo reconhecimento do status linguístico especial da população escolar surda. Cap. III, p. 77-101 In: SÁ, Nídia Regina Limeira de (Org.). Surdos: qual escola? Manaus: Editora Valer e Edua, 2011.302p. ISBN 978-85-7401-558-3. Disponível em: http://www.socepel.com.br/_arquivos/LIVRO_SOBRE_SURDOS/Surdos_Qual_Escolar.pdf $>$. Acesso em 23/03/2014.

CARVALHO, Rosita Edler. Um olhar através da Convenção sobre os Direitos das Pessoas com Deficiência da ONU: novas perspectivas e desafios. Palestra proferida 
durante a III Conferência Nacional da Pessoa com Deficiência, no Eixo de análise: Educação, em 2012.

DISTRITO FEDERAL. Lei n. ${ }^{\circ}$ 5.016, de 11 de janeiro de 2013. Lei que estabelece diretrizes e parâmetros para o desenvolvimento de políticas públicas educacionais voltadas à educação bilíngue para surdos, a serem implantadas e implementadas no âmbito do Distrito Federal. Diário Oficial do Distrito Federal, Brasília, 15 jan. 2013. Seção 1.

FENEIS. A educação que nós, surdos, queremos. Revista da Feneis, Rio de Janeiro, ano 5, n. 25, p. 25, abr./set. 1999. Edição Especial.

FERNANDES, Sueli de Fátima. Letramento na educação bilíngue para surdos: caminhos para a prática pedagógica. In: FERNANDES, Maria Célia Lima; MARÇALO, Maria João; MICHELETTI, Guaraciaba (Org.). A língua portuguesa no mundo. São Paulo: FFLCH, 2008, p. 1-30. Disponível em: < http://www.fflch.usp.br/dlcv/lport/pdf/slp27/06. pdf $>$. Acesso em: 23/03/2014.

. Práticas de letramento na educação bilingue para surdos. Curitiba: SEED, 2006. CDU376: 800.95(81). Disponível em: <http://www.cultura-sorda.eu/resources/ Fernandes_praticas_letramentos+surdos_2006.pdf >. Acesso em: 23/03/2014.

. Surdez Linguagem: é possível o diálogo entre as diferenças? Dissertação (Mestrado em Lingüística de Língua Portuguesa) - Universidade Federal do Paraná, Curitiba, 1998.

FERREIRA-BRITO, Lucinda. Por uma gramática das línguas de sinais. Rio de Janeiro: Tempo Brasileiro, 1995.

LACERDA, Cristina Broglia Feitosa de. Um pouco da história das diferentes abordagens na educação dos surdos. Cad. CEDES [online]. 1998, v.19, n. 46, p. 68-80. ISSN 01013262. Disponível em: http://dx.doi.org/10.1590/S0101-32621998000300007. Acesso em: 23/03/2014.

MOURA, Maria Cecília de. A escola bilíngue para surdos: uma realidade possível. Cap. VII, p.155-168. In: SÁ, Nídia Regina Limeira de (Org.). Surdos: qual escola? Manaus: Editora Valer e Edua, 2011. 302p. ISBN 978-85-7401-558-3. Disponível em: http:// www.socepel.com.br/_arquivos/LIVRO_SOBRE_SURDOS/Surdos_Qual_Escolar. pdf>. Acesso em 23/03/2014.

PERLIN, Gladis; MIRANDA, Wilson. A performatividade em educação de surdos. Cap. IV, p. 101-117. In: SÁ, Nídia Regina Limeira de (Org.). Surdos: qual escola? Manaus: Editora Valer e Edua, 2011. 302p. ISBN 978-85-7401-558-3. Disponível em: http:// www.socepel.com.br/_arquivos/LIVRO_SOBRE_SURDOS/Surdos_Qual_Escolar. pdf>. Acesso em 23/03/2014.

QUADROS, Ronice Müller de. O ‘bi’ do bilingüismo na educação de surdos. In: Surdez e bilingüismo. 1 ed. Porto Alegre: Mediação, 2005, v.1, p. 26-36. 
.Educação de surdos: aquisição da linguagem. Porto Alegre: Artes Médicas, 1997.

SÁ, Nídia Regina Limeira de (Org.). Surdos: qual escola? Manaus: Editora Valer e Edua, 2011.302p. ISBN 978-85-7401-558-3. Disponível em: http://www.socepel.com.br/arquivos/LIVRO_SOBRE_SURDOS/Surdos_Qual_Escolar.pdf $>$. Acesso em 23/03/2014.

SÁNCHEZ, Carlos. Os surdos, a alfabetização e a leitura: sugestões para a desmistificação do tema. Conferência. Secretaria de Estado de Educação do Paraná: Departamento de Educação Especial, 2002. (Mimeo).

SKLIAR Carlos. Uma perspectiva sócio-histórica sobre a psicologia e a educação dos surdos. In: SKLIAR, C. (Org.). Educação e Exclusão. Porto Alegre: Mediação, 1997/2004.

SOUZA, Regina Maria. Que palavra te falta? Lingüística, educação e Surdez. São Paulo: Martins Fontes, 1998.

STOKOE, William L. Sign language structure: an outline of the visual communication systems of the American deaf. In: Studies in Linguistics, Occasional Papers, n. 8. Buffalo, New York: University of Buffalo Press, 1960.

Texto recebido em $1^{\circ}$ de julho de 2014. Texto aprovado em 08 de agosto de 2014. 